Note: This article will be published in a forthcoming issue of the Journal of Sport Management. This article appears here in its accepted, peer-reviewed form, as it was provided by the submitting author. It has not been copy edited, proofed, or formatted by the publisher.

Article Title: Exploring the Utility of Collaborative Governance in a National Sport Organization

Authors: David Shilbury ${ }^{1}$ and Lesley Ferkins ${ }^{2}$

Affiliations: ${ }^{1}$ Sport Management Program, School of Management \& Marketing, Deakin University, Melbourne, Australia. ${ }^{2}$ Department of Sport, Unitec, Auckland, New Zealand.

Running Head: Collaborative Sport Governance

Journal: Journal of Sport Management

Acceptance Date: August 13, 2014

C2014 Human Kinetics, Inc.

DOI: http://dx.doi.org/10.1123/jsm.2014-0139 
"Exploring the Utility of Collaborative Governance in a National Sport Organization" by Shilbury D, Ferkins L Journal of Sport Management

(C) 2014 Human Kinetics, Inc.

\section{Exploring the Utility of Collaborative Governance in a National Sport Organization}

Running Head: Collaborative Sport Governance

\section{David Shilbury}

Deakin University

and

LesleyFerkins

Unitec

David Shilbury is with the sport management program in the School of Management \& Marketing at Deakin University, Melbourne Australia. E-mail: shilbury@deakin.edu.au Lesley Ferkins is with the Department of Sport, Unitec, Auckland, New Zealand 
"Exploring the Utility of Collaborative Governance in a National Sport Organization" by Shilbury D, Ferkins L

Journal of Sport Management

(C) 2014 Human Kinetics, Inc.

\begin{abstract}
This paper presents the outcomes of an 18-month developmental action research study to enhance the governance capability of a national sport organization. Bowls Australia, the national governing body for lawn bowls in Australia, includes nine independent state and territory member-associations. An intervention was designed and implemented with the Bowls Australia Board. The purpose of the intervention was to enact collaborative governance to overcome a perceived cultural malaise in the governance of the sport. This study is one of the first to examine collaborative governance in a federal sport structure. Results demonstrate the utility of collaborative governance to overcome adversarial national, member-state relations for the purpose of establishing a common and unifying vision for bowls, while also enhancing governance capability. This study identified the importance of collective board leadership in governance decision-making throughout the sport. It also highlights future research directions in relation to collective board leadership in federal governance structures.
\end{abstract}

Keywords: collaborative governance, non-profit boards, action research, leadership 
"Exploring the Utility of Collaborative Governance in a National Sport Organization" by Shilbury D, Ferkins L

Journal of Sport Management

(C) 2014 Human Kinetics, Inc.

Collaborative governance theory and practice has its origins in public administration and, more specifically, the need for government to work with multiple stakeholders to deliver major projects and services to communities (Ansell \& Gash, 2008; Emerson, Nabatchi, \& Balogh, 2012; Thomson \& Perry, 2006). Thomson and Perry (2006) noted, in relation to American public administration, that the roots of collaboration are grounded in "competing political traditions: classic liberalism and civic republicanism" (p. 20). The authors contend that "Classic liberalism, with its emphasis on private interest, views collaboration as a process that aggregates private preferences into collective choices through self-interested bargaining" (p. 20). In other words, a variety of public and private organizations enter into agreements to achieve goals that further their organizational interests.

"Civic republicanism, on the other hand, with its emphasis on a commitment to something larger than the individual (whether that be a neighborhood or state), views collaboration as an integrative process that treats differences as the basis for deliberation" (Thomson \& Perry, 2006, p. 20), in that some form of shared understanding or action emerges for the greater good of community or state. Regardless of the ideological perspective, ultimately, the result of collaborative arrangements requires the implementation of governance protocols designed to establish a set of rules for decision-making in relation to the objects of a collaborative entity, and to provide oversight and monitoring of the progress of agreed goals.

Although grounded in public administration, collaborative governance clearly has wider application beyond this sphere, as is argued in this paper. The application of collaborative governance is relevant to national and state sport organizations embedded in systems where sport is supported by government policy and funding, as is the case in Australia, New Zealand, Canada, the United Kingdom and parts of Europe. In this case, sport is considered an important activity to fund, and is managed by non-profit member-based 
"Exploring the Utility of Collaborative Governance in a National Sport Organization" by Shilbury D, Ferkins L

Journal of Sport Management

(C) 2014 Human Kinetics, Inc.

organizations charged with delivering sporting opportunities to the community. Moreover, Australian national sport organizations (NSOs) are, typically, composed of separate legal entities at state and territory level, and are thus governing within a federal model.

In reality, each member association, in governance terms, is charged with ensuring its ongoing operation is commensurate with the objects of the association. Despite all member associations being constitutionally aligned with the national governing body, it is possible for each state or territory association to develop its own strategy and approach to developing a sport in its designated geographic region. Therefore, the aggregation of individual approaches to developing a sport is not guaranteed to accord with the view espoused by a NSO (Shilbury, Ferkins, \& Smythe, 2013). Ironically, while good governance principles may be adhered to in terms of making decisions in the interest of the member association to which directors are elected, the broader positioning, development and strategic direction of the sport may be compromised as a consequence. This scenario is repeated in a plethora of Australian sport organizations (Hoye \& Doherty, 2011), as well as in other countries (Henry \& Lee, 2004; Taylor \& O'Sullivan, 2009), and serves to illustrate how the tenets of collaborative governance can be ultilized to enhance governance for the greater good of the sport.

Bowls Australia (BA), the research site for this study, is the peak body for lawn bowls in Australia and is composed of nine member associations, which include seven state, and two territory associations broadly reflecting the federal form of Australian government. Each member association is a separate legal entity, but recognizes BA as the national governing body. Prior to 2011, the BA Board was composed of delegates nominated as representatives of the State Member Associations (SMAs). This is no longer the case, and, although the conflicts inherent in a delegate system of governance have been removed, the Board is still required to work with and through the SMAs to develop the sport throughout Australia. 
"Exploring the Utility of Collaborative Governance in a National Sport Organization" by Shilbury D, Ferkins L

Journal of Sport Management

(C) 2014 Human Kinetics, Inc.

The purpose of this paper is to communicate the outcomes of a developmental action research study aimed at enhancing the governance capability of the BA Board. Specifically, the aims of this study were to: a) identify what meaning members of a sport board attach to the concept of governance capability; b) identify what factors both constrain and enable governance capability of sport boards; c) identify what actions can be taken to develop capability of sport boards; and d) consider the implications of such action for governance theory and practice.

Typically, action research progresses through four phases. Phases one and two include issue identification and context analysis, phase three is the intervention and action stage of the study and phase four is the evaluation of the intervention (Coghlan \& Brannick, 2010). The intervention (phase three) describes the actions agreed to (and implemented) between the BA Board and research team to enhance board capability. Given the nature of action research, the main theory driving the intervention is often not known until an intervention has been agreed to between the participants and researchers (Gustavsen, 2006). The early sections of this paper provide background to the main theoretical perspective to emerge from the intervention to assist the reader contextualize both BA and bodies of knowledge relevant to the problem examined. In this way, a deliberate intention was to achieve interplay between theory and practice from the outset so that theory might inform practice and, in turn, practice might be instructive for theory development (Heron \& Reason, 2006).

The main theoretical perspective to emerge from this study was grounded in collaborative governance and how this approach shapes governance and leader behavior. This approach was adopted in response to the Board's view that there existed a general feeling of malaise towards governance at all levels of the sport. Subsequently, the decision was taken to use the strategic planning process not only as a means to develop a plan for the entire sport, but also as a mechanism for cultural change by utilizing and seeking to embed a collaborative 
"Exploring the Utility of Collaborative Governance in a National Sport Organization" by Shilbury D, Ferkins L

Journal of Sport Management

(C) 2014 Human Kinetics, Inc.

approach to governance. Thus, a process was undertaken which also involved State Member Association directors in governance discussions with the view to monitoring and recording BA Board behaviors and attitudes to governance and the subsequent impact on SMAs.

This paper considers collaborative governance and its relevance to sport governance in a system grounded in a federal model such as that used in Australia. The paper then outlines the method and results by presenting the four phases of action research noted above, followed by a discussion of the practical and theoretical outcomes. Findings from this study demonstrate how collaborative governance enhanced the capability of the BA Board by overcoming high levels of SMA distrust and a lack of cohesion in the sport. This paper adds to the limited knowledge about the application of collaborative governance in a federal sport structure by articulating the constraints on adopting such an approach in the first instance. Specifically, it also highlights how board leadership shaped member association behavior and the need for a deeper understanding of collective board leadership. This outcome also reinforces the call by Erakovic and Jackson (2012) to promote a stronger research focus on examining leadership in governance and governance in leadership.

\section{Collaborative Governance and its Relevance to Sport Governance}

Ansell and Gash (2008) defined collaborative governance theory as, “A governing arrangement where one or more public agencies directly engage non-state stakeholders in a collective decision-making process that is formal, consensus-oriented, and deliberative and that aims to make or implement public policy or manage public programs or assets" (p. 544). Although not a public agency, BA ultimately has the mandate of engaging non-state stakeholders (i.e., member associations) in collective decision-making processes that are deliberative and consensus-oriented. Hence, collaborative governance has merit in terms of its application to the governance of sport organizations existing within a federal model. 
"Exploring the Utility of Collaborative Governance in a National Sport Organization" by Shilbury D, Ferkins L

Journal of Sport Management

(C) 2014 Human Kinetics, Inc.

This case is reinforced by Robertson and Choi (2012) when they stated, "In general, then, collaborative governance refers to a group of interdependent stakeholders ... who work together to develop and/or implement policies to address a complex, multi-faceted problem or situation" (p. 84). In this instance, the primary stakeholders are the member associations, yet they are clearly a group of interdependent organizations who should be working together to articulate a clear strategic direction for the sport of bowls in Australia. Ultimately, setting direction for the sport is the role of the respective member association boards and can either be done in isolation or collaboratively. This is a critical challenge for the governance of sport organizations such as BA.

Sport governance as a term has typically emerged when referring to the practice of governance applied to sport organizations in the sport context (Hoye \& Cuskelly, 2007). Specifically, Ferkins, Shilbury, and McDonald (2009) defined sport governance as; "The responsibility for the functioning and overall direction of the organization and is a necessary and institutionalized component of all sport codes from club level to national bodies, government agencies, sport service organizations and professional teams around the world" (p. 245). One of the central features of sport governance is the need for adherence to a common set of rules on how a sport and its variations are played. This explains the historical hierarchical requirement for an international governing body, national governing bodies, state or regional governing bodies (depending on country structure) and, finally, clubs.

As sport has professionalized, this rather basic need for governance has blossomed into the full range of functions normally seen in the corporate and non-profit sector. As scholars have noted, typically, old sport structures and customs grounded in amateur traditions have not kept pace with professionalization (Shilbury \& Ferkins, 2011). These changes have led to a variety of tensions between volunteer decision-makers and full-time paid staff (Shilbury, 2001). Consequently, decision-making processes exist in an increasingly 
"Exploring the Utility of Collaborative Governance in a National Sport Organization" by Shilbury D, Ferkins L

Journal of Sport Management

(C) 2014 Human Kinetics, Inc.

competitive leisure environment where national sport organizations seek to balance increasing commercial forces with the provision of sport for the community (Auld, 1997; Hoye \& Doherty, 2011). Moreover, the federal form of governance based on a delegate system of decision-making is replete with tensions, even though all constituted entities share the same charter to promote and develop a sport (Shilbury et al., 2013). Despite logic that signals collaboration and cooperation as paramount in the governance, management and delivery of sport, there is evidence to indicate that genuine cooperation is often absent (Ferkins \& Shilbury, 2010; Henry \& Lee, 2004; Taylor \& O’Sullivan, 2009).

Interestingly, Ansell and Gash (2008) observed that: "In collaborative governance, stakeholders will often have an adversarial relationship to one another, but the goal is to transform adversarial relationships into more cooperative ones” (p. 547). This adversarial relationship was also identified by Shilbury et al. (2013) when examining the lived experiences of a high-profile sport manager with 30 years of sport governance experience. Using hermeneutic phenomenology the authors recounted numerous examples of this individual's experiences in sport governance. Of the three themes identified in the results, one was labelled adversarial encounters which described the nature of this individual's encounters in a federal model of governance ranging from state level basketball, to national basketball, national cricket and international cricket. The other two themes included volunteer/cultural encounters, and structural encounters.

Through these recounted experiences Shilbury et al. (2013) highlighted the interface between volunteer/cultural and structural encounters, noting how, "Structural encounters describe the reliance on delegate representation and a federal form of governance and how behaviour is shaped accordingly" (p. 8). Significantly, adversarial rather than collaborative behaviors were shown to become culturally ingrained. Behaviors ascend to adversarial levels in response to the increasing commercial pressures confronted by national and state sport 
"Exploring the Utility of Collaborative Governance in a National Sport Organization" by Shilbury D, Ferkins L

Journal of Sport Management

(C) 2014 Human Kinetics, Inc.

organizations during the transition to professionalizing governance and management. As will be described later in this paper, BA directors also complained of adversarial relations, which were largely the result of culturally ingrained behaviors shaped by a history of volunteer administration and a federal structure based on a delegate form of governance.

Regardless of these challenges, focus is increasing on the importance of sport governance by practitioners, key coordinating agencies such as the Australian Sports Commission (ASC), and by scholars investigating governance practices in sport organizations. For example, the ASC has been promulgating good governance practice in sport organizations for more than 15 years, and it recently raised the bar when it released its Mandatory Sports Governance Principles (ASC, 2013) in order to address the tensions noted above and improve the quality of governance. In this document it is stated that, "The time is now here to raise the bar, recognising that organisations that are managing public investment and member interests must have structures in place that reflect a greater level of professionalism ... Good governance is a necessary condition for success” (p. 1).

Two key points emerge from this statement. The first is the need to mandate to raise the bar in terms of governance standards. The second is the recognition of sport as a form of public investment, reinforcing the application of collaborative governance where government has a role in supporting NSOs through policy and funding. Not detailed in the ASC document is what role leadership plays in the governance of sport organizations. This is not surprizing given the focus on governance principles and processes. Moreover, according to Erakovic and Jackson (2012), leadership and governance scholars have rarely engaged with each other. The authors noted that the reason for this variance is that "... leadership and corporate governance draw upon quite disparate roots for their guidance and inspiration - corporate governance is primarily rooted in accounting and commercial law, leadership in the disciplines of psychology and, to a lesser extent, sociology and political science" (p. 69). This 
"Exploring the Utility of Collaborative Governance in a National Sport Organization” by Shilbury D, Ferkins L

Journal of Sport Management

(C) 2014 Human Kinetics, Inc.

is reinforced by the differing frames of reference each scholarly community adopts when studying organizations, with governance researchers motivated by a structural frame emphasizing policies and procedures (Erakovic \& Jackson, 2012), while leadership scholars focus on a human resources frame emphasizing people and interrelationships (Bolman \& Deal, 2003; Erakovic \& Jackson, 2012).

Logically, governance sets the stage for leadership at the top of the organization, although it is not always immediately viewed through this prism, as is evidenced by the lack of reference to leadership in the ASC's Mandatory Sports Governance Principles. "Good leadership can energize governance, while good governance can serve to sustain leadership" (Erakovic \& Jackson, 2012, p. 70), reinforcing the interface between governance and leadership. According to Erakovic and Jackson (2012), governance and leadership intersect in three important areas: "team leadership, the chair's leadership of the board and strategic leadership" (p. 70). Although the first two are important, for the purposes of this present paper, it is the third category of strategic leadership which best captures the outcomes of the action research study with the BA Board, as will be described later in this paper.

This emphasis on improved governance by sport organizations has also been supported by scholars investigating the status of sport governance (e.g., Adriaanse \& Schofield, 2013; Hoye, 2007; Hoye \& Doherty, 2011; Ferkins et al., 2009; Ferkins \& Shilbury, 2010; Shilbury et al., 2013; Taylor \& O’Sullivan, 2009; Yeh, Taylor, \& Hoye, 2009). However, limited attention has been paid to collaborative or systemic governance (Henry \& Lee, 2004), or the role of boards from a leadership perspective in the sport domain. Most of the above work has focused on structure and process.

Complex structural arrangements shape sport governance processes and, given the extent to which federal models impact governance behavior in sport organizations, it is timely to be reminded of the purpose of governance. In relation to structure, Lynn, Heinrich, and 
"Exploring the Utility of Collaborative Governance in a National Sport Organization" by Shilbury D, Ferkins L

Journal of Sport Management

(C) 2014 Human Kinetics, Inc.

Hill (2000) contend that, governance "generally refers to the means for achieving direction, control, and coordination of wholly or partially autonomous individuals or organizations on behalf of interests to which they jointly contribute" (p. 255). This is the challenge that confronts NSOs such as BA, and is recognized by the ASC (2013) through the second of its mandatory principles, which states, "Where sports have a federated structure, all parts of the federation must demonstrate they are working in cohesion and adhere to a strategic direction set by the national entity to maximise the interests of the sport" (p. 2). Principle two also indicates the need for all stakeholders to have input into an agreed strategic direction, thereby raising, once again, the need to enact collaborative governance.

What is less well-known is how to implement collaborative governance arrangements and an understanding of constraints impeding its use. More specifically, there are no studies that examine the use of collaborative governance in the sport governance setting. This paper fills this void, describing an action research study aimed at developing governance capability and resulting in the implementation of collaborative governance within the national/state sport organization setting. The conditions in which this action was taken are described in the following sections.

\section{Method}

\section{Choice of Research Site}

Following previous studies with NSOs (Ferkins et al., 2009; Ferkins \& Shilbury, 2010; Ferkins, McDonald, \& Shilbury, 2010) the research team decided to undertake similar governance-related work with interested Australian national or Victorian state-based sport organizations. An initial letter detailing the aims of the study was sent to 55 national and Victorian state sport organizations. The targeted sports were mainstream national and state sport organizations (NSO/SSO) ranging from the higher profile sports of netball, swimming and athletics to lower profile sports such as archery, water polo and canoeing. 
"Exploring the Utility of Collaborative Governance in a National Sport Organization" by Shilbury D, Ferkins L

Journal of Sport Management

(C) 2014 Human Kinetics, Inc.

In all cases, these sport organizations employed paid staff and received funding from either the ASC or relevant state department of sport and recreation. It was also made clear in the letter to NSO/SSOs that the study would require ongoing commitment by the board for a period of between 12-18 months. Three sport organizations (1 NSO, 2 SSOs) expressed an interest in participating and, after consultations with each of the three organizations, it was agreed that two of the sports would participate. BA was one of the two.

\section{Action Research Phases and Data Collection}

Approaches to action research can vary according to the length of field work (longterm with multiple cycles to short-term between 12-24 months), theoretical grounding (low to high), degree of change (low to high radical change) and the extent of collaboration (low to high) (Ferkins, 2007). The style of action research employed in this study was characterized as short-term field work (commenced August 2011, concluded April 2013), low in radical change and high on collaboration between the BA Board (core research participants) and the research team. This style was largely shaped by the work of Cardno (2003), Heron and Reason (2006), and Coghlan and Brannick (2010) and is best described as developmental action research.

The focus of this style of action research was on developing the BA Board's governance capability. In addition to facilitating an outcome from this focus, the research team monitored and reflected on progress, identified and recorded critical incidents, and constructed and recorded interpretations of change and learning. Within this process, the research team played a role in integrating theory and framing outcomes in theoretical terms so as to both advance sport governance practice and seek insight for theory development. This approach reflected the tenets of the interpretive-constructivist paradigm (Denzin \& Lincoln, 2011) on which the study was grounded. 
"Exploring the Utility of Collaborative Governance in a National Sport Organization" by Shilbury D, Ferkins L

Journal of Sport Management

(C) 2014 Human Kinetics, Inc.

The action research model developed for this study emphasized a cyclical process that allowed for refinement and a deeper exploration of the issues as they were unfolding. This approach also assisted with ensuring the validity of the research process (Cardno, 2003). Figure 1 illustrates the action research model used for this research and shows the four phases through which the study progressed. Phase one, Issue Identification, involved initially meeting with the BA Board and CEO to explore areas in which action could be taken to enhance governance capability. As indicated in the introduction, the broad question was, "How can the BA Board enhance its governance capability?" This question framed the study and its purpose. From the outset, this approach ensured a collaborative approach between the Board and research team, by interactively exploring the meaning of governance capability, what it means to be a strategic board as well as probing the board in terms of its strengths and weaknesses. The interactive nature of this process was enabled via the research team's ability to infuse their theoretical and practical knowledge of governance to explain key terms in order to facilitate a focused discussion on current and future capabilities of the board.

Phase two, Context Analysis, as shown in Figure 1, converged with phase one, as the process of identifying a potential intervention also relied on an interplay between supporting documented evidence and the issues articulated by the BA Board. In this phase, background information on BA was collected to better understand the organization and its operating environment. Examples of documents that assisted in this phase included the current strategic plan, annual reports, the BA annual census of participation and ASC funding details for NSOs.

Phase three is the actual intervention or action taken to address the study question. The Board's collective experiences combined with the research team's experience informed the intervention and its implementation. As discussed in the results section, the project grew to include all SMAs plus others, and the research team met regularly with the BA Board to 
"Exploring the Utility of Collaborative Governance in a National Sport Organization" by Shilbury D, Ferkins L

Journal of Sport Management

(C) 2014 Human Kinetics, Inc.

monitor and reflect on progress and plan for the next stages in phase three. While Figure 1 shows two main interventions, a series of mini-cycles of action also occurred during the 12 months of the action phase (as represented in Table 4). Reflecting and monitoring with the Board occurred after all interventions and actions.

Phase four focused on an evaluation of the intervention and action. During this phase participating board members were interviewed to critically reflect on what occurred and why, and how governance capability had been impacted by the interventions. It should be noted that during the process, inevitably, there were some Board changes as there was an Annual General Meeting (AGM) held in October 2012, nearly two-thirds of the way through the action phase. As three retiring Board members had been part of the early process of identifying the intervention, and had participated in the majority of the intervention, those Board members also contributed to the evaluation phase along with existing Board members who had been on the Board since late 2011 and early 2012.

Coghlan and Brannick's (2010) concept of meta learning was ultilized as a final component of the action research model developed for this research. Figure 1 shows a replication of the mini-cycles placed around the outside of the square to encourage a strategic view of the cycles and phases that took place. This strategic view focused on the content (what was happening); process (how it was happening); and premise (why it was happening). "It is the dynamic of this reflection on reflection that incorporates the learning process of the action research cycle and enables action research to be more than everyday problem-solving. Hence, it is learning about learning - in other words, meta learning" (Coghlan \& Brannick, 2010, p. 12).

Several data generation techniques were used, including document analysis (annual reports, strategic plan, National Bowls Census), meetings with the Board (4 in phases one and two; 4 in phase three), workshops (1 planning workshop with 45 participants, 2 with the state 
"Exploring the Utility of Collaborative Governance in a National Sport Organization" by Shilbury D, Ferkins L

Journal of Sport Management

(C) 2014 Human Kinetics, Inc.

consultative body), evaluation interviews (8 with BA Board members/CEO), participant observation, reflective journaling, video analysis, audio analysis and member checking. Reflective journals and memos were important techniques used to 'make sense' of board meetings, workshops and interviews, and identify gaps in understanding so that research participants could be further consulted (member checking also assisted with validity). In phases one and two, for example, statements relating to barriers and enablers of governance capability were subject to thematic analysis assisting with the emergence of themes in relation to issues identification and context analysis. Summary memos were prepared capturing key points, any decisions made during data generation, as well as the proposed next step (e.g., next meeting or workshop).

Transcripts of the evaluation interviews from the fourth phase were also used as the basis for a thematic analysis of materials. Consequently, data generation “... informed data analysis and vice versa, so the two processes became reciprocally integrated (O'Sullivan, Hocking, \& Spence, 2014, p. 24) to capture, track (via regular journal entries, and electronic organization of documents, interview and workshop notes and transcriptions), analyse, and ultimately tell the story as it unfolded. The research team members shared the facilitation, with one member of the research team leading the initial two phases of the study as well as assuming responsibility for the conduct of the evaluation interviews. The other member facilitated the intervention or action stage of the study, which included the preparation of the strategic plan for bowls in Australia.

\section{Results}

This section presents the results of the fieldwork in each of the four phases used to shape the intervention. The number of bowls' personnel participating in the action stage, or phase three, of the study, is shown in Table 4 later in this paper. 
"Exploring the Utility of Collaborative Governance in a National Sport Organization" by Shilbury D, Ferkins L

Journal of Sport Management

(C) 2014 Human Kinetics, Inc.

\section{Phases One and Two: Issue Identification and Context Analysis}

Background and Context. The national office of BA is located in Melbourne, Australia, and at the time the fieldwork commenced BA employed 15 staff to discharge its charter in the areas of participation, high performance sport, conduct of national events and commercial operations. Staff numbers were boosted in 2012 by the appointment of 16 community development officers based in major cities and regions across Australia. The CEO had been with BA for five years and was an experienced CEO having worked in a number of sport organizations previously, as well as having completed postgraduate qualifications in sport management. BA gross revenue in 2011/12 was $\$ 4.8$ million, an increase of $\$ 861000$ from the previous year (BA, 2012). Revenues included funding from the ASC of $\$ 1.3$ million split almost equally between high performance and participation (ASC, 2012). Operating surplus in $2011 / 12$ was $\$ 6596$ compared to the previous year's result of $\$ 66779$ (BA, 2012).

The BA 2011/12 annual report stated that there was, "an increase in the numbers of participants in the sport of bowls from 853000 to 935000 in 2011” (p. 20), up 9.6 per cent from the previous year. These participation numbers were based on the 2011 National Bowls Census (BA, 2011). Although these numbers appear impressive, they are tempered by a trend towards declining membership in bowling clubs across Australia. Annual reports showed 234 725 members in 2,002 bowling clubs, declining to 221052 in 1,974 clubs in 2010/11, and, by the commencement of the fieldwork, there were 210041 members in 1,961 clubs (BA Annual Reports, 2009/10-2011/12). The larger participation numbers reported in the annual census are attributed to the growing number of casual and recreational bowlers who may ultilize club facilities but not avail themselves of membership at a bowling club.

The Board was composed of nine directors with six elected by SMAs and up to three appointed as independent directors. The constitution allowed the Board to appoint up to three 
"Exploring the Utility of Collaborative Governance in a National Sport Organization" by Shilbury D, Ferkins L

Journal of Sport Management

(C) 2014 Human Kinetics, Inc.

directors with special business acumen and/or technical skill. In terms of setting the scene for the fieldwork, the transition of governance arrangements in 2011 from a delegate form of representation by the SMAs (each member association represented by an appointed delegate) to six directors elected (from any member association) by all SMAs, coupled with the ability of the Board to appoint three independent directors, forms important background to this study. Consequently, governance arrangements were still settling, in that directors were adjusting to the expectation that they held no other formal board positions with the SMAs, and that they were free to think and focus on the overall competitive position of bowls without the constraints and conflicts of having to represent a SMA.

In addition to the Board, BA established the State Consultative Body which is comprised of the SMAs, normally represented by the president and CEO from BA and each state. SMA representatives attend the AGM in October each year and this group exercises its power to vote on who is elected to the Board. This group, as its name implies, acts as the consultative group from which BA seeks input on matters of financial and strategic importance.

Issue identification. Following initial discussions with the CEO in setting up study requirements and collecting background information, the first meeting with the Board occurred on 30 August 2011. At the meeting the overall study purpose and process were explained followed by a facilitated session focused on exploring the notion of a capable board (Table 1), director perceptions of how well the board is doing (Table 2), identifying the constraints on and enablers to achieving the ideal board, as well as considering possible actions in response to these issues (Table 3).

Table 1 shows responses to the first question asking BA directors to identify the attributes of a capable board. Four categories, namely, people, monitoring, strategic role, and relationships with SMAs emerged. Three of the four categories could be expected to arise in 
"Exploring the Utility of Collaborative Governance in a National Sport Organization” by Shilbury D, Ferkins L

Journal of Sport Management

(C) 2014 Human Kinetics, Inc.

most governing scenarios, with the fourth, relationships with SMAs, quite specific to that environment. The identification of the fourth factor was an early portent of where the Board was headed in terms of defining an intervention, as is shown in Table 2, which displays director perceptions of how well the board is doing. Significantly, directors were comfortable with their role in identifying key strategic issues and actions required, but expressed frustrations with their ability to implement strategy, which was also reflected in the challenge over control of decisions by SMA boards. In other words, strategic direction, actions and implementation by SMAs were not necessarily consistent with those espoused in the BA strategy. This was more powerfully expressed in Table 3 where culture emerged as a serious limitation coupled with realization of the barriers and constraints that were reflected in the BA/SMA relationships.

This situation was reinforced by responses to the question - what possible actions can we take? Although too early to determine precise actions, this question was required as a focusing tool to test the linkages between early responses and how the board could enhance its governance capability. Responses to this question included: "Conduct education program with state boards (members, CEOs)"; "Fight the 'culture with the culture' - create a cultural change, education program founded on shared governing role"; "Educate the whole group, sustained, on-going, systemic, strategy-driven - set parameters of reporting (at state level)"; "States report on their strategic outcomes to rest of bowls community"; and, "Have we let them talk and have we asked enough questions?"

It was clear there were some common perceptions about an implicit but, as yet, unarticulated problem. Common ground was noted in the need for cultural change and education, and that the BA/SMA relationship was at the core of whatever issue was in the collective minds of the Board. The focus on issues 'belonging' to the SMAs was balanced somewhat by the last two points in Table 3 under constraints, which focused on 
"Exploring the Utility of Collaborative Governance in a National Sport Organization" by Shilbury D, Ferkins L

Journal of Sport Management

(C) 2014 Human Kinetics, Inc.

communication channels and the degree to which SMAs felt 'invited' to contribute to the national direction for bowls. Moreover, a telling sign was also detected by the researchers in the fourth point in the previous paragraph which, in essence, signalled the importance of hierarchy and where control could/should be exerted over the SMAs if they were required to be more accountable to the bowls community. The first session concluded with some uncertainty as to what exactly was meant by being "hamstrung by culture". That became the logical starting point for the second facilitated session in October 2011.

The next facilitated session elaborated on perceived constraints to achieving the ideal notion of governance capability. In other words, the intent was to more specifically diagnose the issues identified previously (i.e., we are hamstrung by what specifically?). The session also sought to consider options for action. Responses to this question were somewhat mixed, ranging from a cultural divide between the top and bottom of the sport, being hamstrung by past practices, an old culture that does not recognize strategic governance, and being seen as a sport in panic lurching from crisis to crisis.

Although responses ranged widely, there was evidence of the constraints confronted by bowls in the transition from a 'pastime' to a more professionally organized and delivered sport. Changes made to BA Board composition were not as yet mirrored at SMA level, thereby accounting for a growing cultural divide. This divide is highlighted in the responses to the next question which asked directors to refocus on culture from a governance perspective and to suggest possible actions to overcome the notion of being hamstrung by culture. Responses included: "Changes to the constitution to create a more professional approach to governance"; "Attract quality leaders to govern our sport"; "Structured committee meetings, driven by strategy"; "The need for an education process - education about 'the journey' bowls has been on has not been specific to club members; "Change the board composition"; and, "Systemic and formal change". 
"Exploring the Utility of Collaborative Governance in a National Sport Organization" by Shilbury D, Ferkins L

Journal of Sport Management

(C) 2014 Human Kinetics, Inc.

When asked at what level change should occur, three of the five responses targeted the SMAs, with a minor view that change should commence at club level. For example, one response illustrated this sentiment by stating, "our only option is to keep nibbling away at SMA level/boards". In summarizing progress in readiness for the final facilitated meeting aimed at identifying an appropriate intervention, the following was constructed by the research team (using participant statements) for consideration by the participants.

We are hamstrung by an amateur culture and lack of aspiration to grow and professionalize the sport. There is a cultural divide between the top and the bottom of our sport. We need to better communicate the journey bowls has been on to professionalize, develop and grow. We need to communicate the benefits of our professionalization story to the bowling community so that we can attract those who can help govern strategically; so we can attract those who can help drive our professionalization strategy. We need to begin at the SMA level.

For the researchers, it was clear that the transition from an old amateur culture to a more contemporary professional approach was not being embraced at the same pace across the sport. Despite changes to governance structures at BA level, similar changes were not necessarily occurring at levels below. Evidence of this divide was clearly portrayed in the description of a "cultural divide" in Table 2 and the need to change and educate the SMAs. Lack of progress towards professionalization by the SMAs was seen as a major constraint by the BA Board, yet, embedded in this analysis were underlying concerns of the role BA had played in facilitating this development. This was evidenced by the Board's desire to communicate and tell the story of professionalizing better than had been the case and the stated need to better educate SMAs about the journey bowls has been on in relation to professionalization.

What followed at the December 2011 meeting was a discussion on what specific, yet impactful, actions could be taken to enhance the governance capability of the board. The discussion examined how education could be used as a possible solution. Specifically, what 
"Exploring the Utility of Collaborative Governance in a National Sport Organization" by Shilbury D, Ferkins L

Journal of Sport Management

(C) 2014 Human Kinetics, Inc.

type of education was needed, about what, and with whom? Table 3 summarizes the responses, and three other questions focused on key issues and identifying the enablers and barriers to achieving an educated membership.

The type of education required was clearly aimed at SMA level and predominantly focused on changing governance structures, behaviors and processes. It was also recognized that education was aligned with cultural change. Despite a series of issues and constraints arising, the question was asked by one director whether the formulation of the next strategic plan could be used as the vehicle through which education and cultural change could be facilitated. Fortuitously, this director had recognized that the current plan was due to expire at the end of 2012 which allowed time for the next strategic plan to be developed in collaboration with SMAs.

The advantages and disadvantages of this approach were then explored. The outcome was unanimous agreement to use the strategic planning process as a mechanism to educate and influence the culture of the bowls community regarding the governance of the sport. On reaching agreement the Board asked the research team to work with the CEO to map out how the planning process could be used to educate, inform and commence a process of cultural change by exploring the utility of collaborative governance. 
"Exploring the Utility of Collaborative Governance in a National Sport Organization" by Shilbury D, Ferkins L

Journal of Sport Management

(C) 2014 Human Kinetics, Inc.

\section{Phase Three: Intervention and Actions}

At the 22 February 2012 board meeting it was agreed that a two-day strategic planning workshop could be held in April to coincide with an already scheduled meeting of the State Consultative Body. This provided the ideal platform to launch the process and run a planning workshop with this body plus invite a number of other stakeholder representatives such as sponsors, players, coaches, and officials from local bowls clubs. It would be the first time that the bowls community had conducted a national face-to-face meeting dedicated to whole-of-sport strategy development.

It was also agreed that this would be a strategic plan for bowls in Australia, not solely for Bowls Australia, and that it should be finalized and accepted 12 months later at the April 2013 meeting of the State Consultative Body, thereby allowing enough time for genuine input and consultation. Table 4 shows the mini-cycles or actions during the 12-month period as well as the number of participants actively involved at each stage. Although Table 4 shows the dates and timing of events, the actual planning and timing of each event were either subject to already planned meeting dates, or ongoing negotiation between the research team and Board as part of the monitoring and reflection process.

It is not possible within the confines of this paper to describe all that occurred during the mini-cycles shown in Table 4. A brief overview is provided, complemented by a fuller description of the BA Board's mid-project reflections. The April 2012 strategic planning workshop launched the project where it was explained to participants that the workshop was part of a research project with the BA Board that had identified the need for a more collaborative approach to determine the future direction of bowls in Australia. Relevant research ethics procedures were attended to before explaining that this plan was being formulated as a plan for bowls in Australia, not solely for BA. In other words, a collective vision was sought for the future direction of bowls in Australia. 
"Exploring the Utility of Collaborative Governance in a National Sport Organization" by Shilbury D, Ferkins L

Journal of Sport Management

(C) 2014 Human Kinetics, Inc.

To ensure that the work commenced during the planning workshop was ongoing and consistent with a collaborative approach, strategic sub-groups were formed to advance various sections of the plan. There was some initial resistance to using strategic workgroups to advance the plan, mainly grounded in the difficulty of convening personnel from around Australia to meet face-to-face. When it became clear that technology could overcome the need for face-to-face meetings resistance, to a large extent, subsided.

Table 4 also displays the schedule of governance consultation which included boardto-board meetings, two State Consultative Body meetings and engagement with BA staff. It was not practically possible to convene a full meeting of the Board to meet with all the SMA boards. This occurred with four SMAs and, in instances where this was not possible, some BA directors joined the CEO during these meetings. The goal of each meeting was to allow the respective SMA to share their major strategic issues, and then work through the draft plan.

As the Board had identified staff engagement as critical to the development of the plan, staff members, beyond the senior executive team, were invited to engage with the plan through one meeting with the full Board, and another convened by the CEO. The State Consultative Body met two days after the Board met with staff, and a facilitated session again focused on each section of the plan. This meeting was the first opportunity for all the SMAs to collectively meet with the Board and research team following the April planning workshop. By this stage of the process, the plan was being refined and consolidated. The next meeting with the State Consultative Body was in April 2013 where, following a final summary presentation, the plan was unanimously adopted. With the adoption of the plan at the April 2013 meeting, the intervention phase via the action research formally came to its conclusion. What remained was the evaluation of the fieldwork to date. 
"Exploring the Utility of Collaborative Governance in a National Sport Organization" by Shilbury D, Ferkins L

Journal of Sport Management

(C) 2014 Human Kinetics, Inc.

BA Board Meetings and 12-Month Reflections. The research team attended four BA Board meetings during the intervention. The first meeting in June 2012 was used to reflect on the planning workshop in April and progress in relation to the strategic workgroups. The August meeting of the Board coincided with the study having commenced 12 months earlier. Consequently, the research team invited Board reflections on progress to that point.

The first question asked of Board members was to reflect on the choice of using the strategic planning process through which to commence cultural change through education. In other words, after 12 months, what do they think now? Responses included: "What we started in Broadbeach (planning workshop) was very positive and it seems to have been continued"; "Some resistance to the process has been worn down"; and, "Willingness of BA to visit states and engage states has been a positive. This has made the states aware of BA and its role and involvement. The outcomes from this have been good and have improved relationships".

These positive reflections were countered by the following observations: "The geographic distribution of the states has made it very expensive"; "It also seems that state representatives are not necessarily feeding back information obtained to their constituents, in some states"; and this response, which articulates issues with trust:

In telephone and online meetings, some people are purporting to be supporting what is going on, while they are not acting in this way and they are not behaving the same way day-to-day as they are in web conferences. Many just think thank goodness that's over and they disappear. Oh yeah, we'll go on with it, but then they don't. And you see that a bit in (State). But at least we are talking with them and hearing them.

Early signs of improvements in BA/SMA interactions were noted by the researchers and included the breaking down of perceptions identified in the adversarial encounters observed during the issue identification phase. Cost to implement a collaborative approach was raised by some BA directors, and, while others thought resistance was eroding, there was 
"Exploring the Utility of Collaborative Governance in a National Sport Organization" by Shilbury D, Ferkins L

Journal of Sport Management

(C) 2014 Human Kinetics, Inc.

still a view that behavior did not always match the rhetoric from the SMAs. In discussing these outcomes the Board noted the importance of ongoing communication, how the past holds people back, and that "cultural change is slow".

The second question asked by the researchers was, "have we let them talk?" All Board members were satisfied that the SMAs and representative stakeholders had been heard, but there was some concern as to "whether they were still talking", a response to the potential fatigue caused by the two rounds of strategic workgroups. Responses to the third question proved to be the most interesting. When asked what are/should BA Board members be doing, there was general agreement that each director had contributed but tried not to dominate, and had let others speak and share ideas, as is indicated by this response: "From Broadbeach, I understood the purpose was to engage states and draw on the CEOs from states, to see what they came up with first, before having our say. X (an SMA CEO) was the leader and I left it to him, as it was about getting them involved."

What emerged from this discussion was a sense that the Board needed to exert more control over the process. Although in agreement with the collaborative approach and the need to let others speak, increasingly, there was a sense that control was being lost, as is shown by this sample of quotations. "It is our strategic plan. We are a strategic board and we should spend more time on strategic planning. The board should have had greater involvement at an earlier stage and we should have been involved in every aspect of the plan." The additional challenge of managing and maintaining stakeholder interest and input also proved to be frustrating, as this director noted. "I agree. The interest from stakeholders has died off. The board now should be engaging more in it, with the staff. They are the ones who will have to deliver it."

In reflecting on the discussions from this review session, the research team observed a sense of hierarchy returning and how the Board expressed a strong interest in taking control 
"Exploring the Utility of Collaborative Governance in a National Sport Organization" by Shilbury D, Ferkins L

Journal of Sport Management

(C) 2014 Human Kinetics, Inc.

of the planning process from this point forward, leading others through planning, rather than seeking their ongoing input. However, what they agreed to was further consultation and input from BA staff, to workshop the draft plan with the State Consultative Body in October, and a commitment to the remaining board-to-board meetings. Nonetheless, the residual anxieties and frustrations relating to control were noted by the research team and were monitored during the remaining eight months of the intervention, which led to the adoption of the strategic plan in April 2013. Following adoption of the plan, the study moved to phase four, the final evaluation interviews.

\section{Phase Four: Final Evaluation}

Seven of nine directors plus the CEO participated in the evaluation interviews. Director resignation and an existing casual vacancy explain the number of interviews conducted. Enacting collaborative governance in a network of NSO/SSOs would appear to be an obvious approach to adopt. However, when asked why this approach had not been tried, there was initially little explanation forthcoming. Responses typically revealed a sense of bemusement, including: "Can't answer the question as to why they weren't involved previously"; "I think it's a good question..."; and, "You are right, it is not rocket science". When addressing this question in more depth, it was noted that BA had, in formulating the previous strategic plan 2008-12, invited consultation, but the consensus was that there were barriers that prevented the effective implementation of that plan. For example, one director noted the following by stating:

What I do know is that the board had spent some weeks and many hours in putting together a plan that we thought was a reasonable strategic plan. I thought it was really our plan and it took an awful lot to get the SMAs to sign up to it or take any kind of ownership at all. We suffered really from not involving the SMAs right from the start, and when it came to getting them to sign-off on an MOU on the whole process, we ended up with a hell of a fight. 
"Exploring the Utility of Collaborative Governance in a National Sport Organization" by Shilbury D, Ferkins L

Journal of Sport Management

(C) 2014 Human Kinetics, Inc.

The inability to implement a collaborative approach was mentioned by one respondent when describing the culture embedded in the federal model. "I actually described BA as the final resting place of people who have got onto a club committee, then progressed to a club president and then to the district and then onto a committee and then got to the state board. Then, my goodness me, I've just got to get to that national body ...". In elaborating on the final resting place metaphor, this respondent noted an attitude that, in part, explained a constraint to collaborative governance. He further stated, "I've got here, so now you ... [people] are going to do what I say, an attitude ... of I've got here and we're just bowls organizing gurus now". The control associated with this perspective helps explain why a relatively obvious concept such as collaborative governance was sidelined by a variety of structural impediments and individual motivations.

The intervention focused on using the strategic planning process as a mechanism to educate and change the culture of the governance of bowls. In settling on this action, it was also recognized that cultural change was a long-term goal, and it was unlikely that complete change would be rendered in 12 months. However, it was possible that some evidence of change might be noted. When asked to reflect on the problem and intervention, all directors agreed that it was an accurate assessment of an important governance issue. Words including, "absolutely certain", "very appropriate", and "pretty accurate assessment" typified the range of responses.

One of the major outcomes sought was the adoption, acceptance and implementation of a strategic plan for bowls in Australia. Embedding change was sought by securing agreement to common vision and mission statements plus six strategic priority areas that all SMAs would use to shape their state-based plans. This outcome would address one of the major governance concerns of directors when they noted a lack of control and consistency in the strategy-setting function of the board. Education, via the planning process, was aimed at 
"Exploring the Utility of Collaborative Governance in a National Sport Organization" by Shilbury D, Ferkins L

Journal of Sport Management

(C) 2014 Human Kinetics, Inc.

impacting cultural change in governance decision-making, moving it from an adversarial to a collaborative approach.

Progress made in relation to educational and cultural change was explored with the directors. The decision to use the strategic planning process as the means to educate and commence cultural change was acknowledged as appropriate, as it clearly contributed to the desired outcomes. One response, representative of the group's overall assessment, stated that, "The decision to use the strategic planning process as a tool for education to bring about cultural change was the right decision in my view. It has proven to be an effective means of enhancing engagement, collaboration and co-operation with all BA stakeholders".

On seeking to identify tangible evidence of changes to culture and attitudes between BA and SMAs, it was clear that the collaborative approach had led to a greater sense of cohesion and cooperation with meetings being reported as "much calmer and nicer", and that "there is more trust because people were now working together". The following response describes the degree of change to attitudes, and consequently culture:

There's been a definite change in the relationship between BA and the states and I think a lot of that, or just about all of that, can be put down to the collaborative approach that we've taken with this project. There's a definite thawing, I suppose, of atmosphere at meetings compared to what there was, and I think a lot of that is because the states have been involved in working together.

Perhaps the most tangible outcome beyond the above perspectives was the adoption of the Bowls in Australia plan by the State Consultative Body at its April 2013 meeting. Despite the success of the intervention and outcomes consistent with attitude and cultural change, sustainability remained a challenge. On the question of whether the collaborative approach could be maintained there were mixed views. Three issues were identified as central to sustainability. The first related to volunteer turnover and an ability to maintain a similar collaborative approach via planning workshops. One director observed, "I have my doubts 
"Exploring the Utility of Collaborative Governance in a National Sport Organization" by Shilbury D, Ferkins L

Journal of Sport Management

(C) 2014 Human Kinetics, Inc.

about whether the cultural change can be sustained unless a similar process is rolled out every couple of years, purely because of the turnover of both volunteer and paid personnel". The second issue identified was communication, and it was noted that regular communication was going to be important to maintaining the close contact. The third and perhaps most insightful observation came from one director, stating that:

Everyone has some responsibility around the plan. It's about systemizing the process - not just one person taking it on. 'Systemizing' the process is critical as it is one method by which a collaborative approach can become ingrained in the sport, which is an important response to a culture that has reinforced the view that we've been doing things like this for the last 20 plus years and why do we want to change it?

A further response to the issue of systemizing a collaborative approach was raised by another respondent, stating, "Continuing that theme of whenever there's an important strategic initiative to deliver, we need to form a working party, which some would argue is a bit clunky, but I think it's the only way. We're not in a position to fund initiatives from top down".

From the researchers' perspective (in using this evidence), clearly, board thinking had shifted in relation to how the study had contributed to collaborative governance and cultural change generally. One director captured the overall reaction, stating, “... there's been quite a shift in thinking from ... [being] focused on your own backyard at a national level. Now there's this philosophy and thinking of shared services". Moreover, the portent of genuine partnerships with the SMAs had begun to pervade thinking, as this respondent noted, “ ... we've been able to introduce this thinking at the board table nationally ... we're thinking of the implications on the states, and how we can develop a partnership. It's a partnership approach on everything. So the thinking has switched".

As one director noted, the process highlighted to the Board the need "to communicate much more effectively with their SMAs. I think going through the process ... highlighted 
"Exploring the Utility of Collaborative Governance in a National Sport Organization" by Shilbury D, Ferkins L

Journal of Sport Management

(C) 2014 Human Kinetics, Inc.

that, in their leadership role, they couldn't do it in isolation; they had to govern in conjunction with their state bodies". It also emphasized the tension identified by the board at the issue identification stage, where it was shown that board thinking was focused on the weaknesses of the SMAs and their inability to conform to BA strategy. A minority view was also expressed questioning the efficacy of channels of communication to SMAs and whether they felt 'invited' to contribute. Establishing a process of collaborative governance clearly tested the existing logic that SMA intransience explained governance difficulties. It sharply brought into focus the need for the board to establish a collaborative culture, which, ironically, proved more effective in allowing the Board to demonstrate the leadership they thought they should as the national governing body. Collaboration with the SMAs was identified as paramount.

\section{Discussion}

Given the origins of collaborative governance in public administration and Thomson and Perry's (2006) observations in relation to competing political traditions, BA and its member associations appear to demonstrate a curious mix of classic liberalism and civic republicanism. On the one hand, BA reflects an emphasis on "private interest" viewing collaboration as a process that aggregates private preferences through self-interested bargaining (Thomson \& Perry, 2006). As shown in the early sections of this paper and reinforced during the intervention, BA's history, and, therefore, "starting position" for this study has traditionally been aligned with aggregating collective choices through self-interest. On the other hand, there was also something compelling from within the sport that recognized the ideal of civic republicanism, namely, that the sport is larger than the individual, or, in this case BA and the SMAs, while accepting collaboration as providing the potential for an integrated process contributing to a national strategy for bowls. It was the ideological perspective grounded in civic republicanism that appeared to explain why the bowls community agreed to explore a collaborative process. In other words, despite 
"Exploring the Utility of Collaborative Governance in a National Sport Organization" by Shilbury D, Ferkins L

Journal of Sport Management

(C) 2014 Human Kinetics, Inc.

entrenched self-interests, the greater good of the sport and its contribution as an important leisure outlet for older Australians unlocked the potential for governance reforms. This curious mix of ideological perspectives also appears to have been shaped by structural challenges embedded in a federal model of governance.

This structural challenge can also be explained in institutional design terms, as is shown in Figure 2, which displays a model developed by Ansell and Gash (2008) following their meta-analytical study of the collaborative governance literature. This model also helps explain outcomes from this study. Institutional design "refers to the protocols and ground rules for collaboration" (Ansell \& Gash, 2008, p. 555) and, as has been demonstrated, the adversarial nature, or self-interest perspective, of the federal model of governance which sets the tone for these protocols and ground rules.

The influences that led the Board to explore the application of collaborative governance are illustrated within the three starting conditions shown in Figure 2. The most obvious of these to emerge from this study was the history of conflict and low levels of trust associated with the governance of bowls, both of which were reinforced during phases one and two (identifying the intervention), and phase four (the evaluation interviews). The significance of these behaviors has been previously described as adversarial by Ansell and Gash (2008) and Shilbury et al. (2013) and, typically, involves jockeying for power, control and resource acquisition, in particular, from the larger SMAs which have a stronger membership base from which to challenge the leadership of BA. Moreover, the history of conflict and distrust can also be explained by the erratic pace of change in governance reform across the sport. Despite changes to governance structures at BA level, similar changes were not necessarily occurring at levels below, hence a clash of cultures.

Ansell and Gash (2012) highlight the importance of leadership, and facilitative leadership in particular, in collaborative governance, as is illustrated in Figure 2. In this 
"Exploring the Utility of Collaborative Governance in a National Sport Organization" by Shilbury D, Ferkins L

Journal of Sport Management

(C) 2014 Human Kinetics, Inc.

present study the role of facilitative leadership was fulfilled by the research team by coming from outside the bowls community and adopting a neutral role. Sustainability of the collaborative approach is grounded in the ability of the bowls community to produce what Ansell and Gash (2012) describe as organic leaders, or "leaders that come from within the community of stakeholders" (p. 6). They will likely be individuals, who, while not necessarily "neutral, will have an overriding interest in promoting collaboration" (Ansell \& Gash, 2012, p. 6).

A key finding of the present study is that although facilitative leadership could be about an individual or individuals, in reality, it is about the BA Board and its ability to energize governance through leadership (Erakovic \& Jackson, 2012). This study revealed that although the Board was of the view that the SMAs were recalcitrant in terms of governance malaise, in actual fact, how the Board chose to lead shaped how the SMAs behaved. Mere consultation, as was undertaken during the 2008-12 strategic plan, was not enough; it needs to be genuine collaborative governance characterized by robust, deliberative two-way dialogue and shared decision-making.

Collaborative governance, with its emphasis on engaging key stakeholders and decision-making that is consensus-oriented and deliberative, has potential to re-shape governance behaviors exhibited by directors of national and state sport organizations. A key component of the Ansell and Gash (2008) definition is the focus on deliberative decisionmaking. As Robertson and Choi (2012) contend, this develops "a better understanding of what differences stakeholders really care about and why" (p. 87) as evidence of open and robust debate encouraging the quest for consensus, but it must be led by the national board.

BA Board leadership, or strategic leadership as espoused by Erakovic and Jackson (2012), is therefore significant, as the Board has the influence to ensure that collaborative processes are systemized and, consequently, more likely to be sustained. Sustaining a 
"Exploring the Utility of Collaborative Governance in a National Sport Organization” by Shilbury D, Ferkins L

Journal of Sport Management

(C) 2014 Human Kinetics, Inc.

collaborative approach was raised by some board members in the evaluation interviews as a potential difficulty, given volunteer director and potential executive turnover. Based on the findings of this study, board leadership needs to focus on developing and embedding the core collaborative processes shown in Figure 2. Systemizing core collaborative processes is, arguably, more important in organizations reliant on volunteer decision-makers who may have divergent backgrounds and understandings of business practice, and limited knowledge and time to devote to their governance roles.

Within the core collaborative process box shown in Figure 2, face-to-face dialogue was the key to shaping the outcomes. However, ongoing face-to-face dialogue after the strategic planning workshop was considered a challenge in a geographically dispersed sport such as bowls. To ensure dialogue could be maintained, some institutional protocols were revisited which had traditionally been grounded in SMAs working in isolation and not actively contributing to a national strategic agenda, apart from the two SMA meetings per year, one of which was the AGM.

This challenge was overcome at the planning workshop by agreeing to the use of technology to activate strategic workgroups. It was further complemented by the board-toboard meetings and the normal meeting schedule of the State Consultative Body. As was shown in the evaluation interviews, the combination of these approaches built trust and engendered a sense of shared ownership, but was tempered by a view on whether a collaborative approach could be sustained. As Mandell and Keast (2007) observed, the effectiveness of new arrangements depends on "whether the members of a collaborative network are able to develop new processes that will lead to new ways of working, new structural arrangements and integration of the members into a new whole, which will lead to the accomplishment of innovative solutions" (p. 579). As shown in the evaluation interviews, directors were supportive of these new arrangements, largely based on the need to sustain 
"Exploring the Utility of Collaborative Governance in a National Sport Organization" by Shilbury D, Ferkins L

Journal of Sport Management

(C) 2014 Human Kinetics, Inc.

collaborative practices to build trust through ongoing face-to-face dialogue, albeit sometimes mediated via technology.

In this study, the intervention was designed to build trust, commitment to the process and a shared understanding leading to immediate outcomes, which included development of the next strategic plan and, finally, the adoption of the plan. To achieve this outcome, face-toface dialogue was central to building mutual respect in terms of interdependence, shared ownership, openness to exploring mutual gains, and arriving at an agreed vision, mission and values for bowls, all of which were based on the sharing of common problems and defining their scope.

Although governance education and cultural change remain important and are an ongoing strategic imperative for bowls at all levels, the way the national Board chooses to lead and address the need for change is paramount. Reverting to an authoritarian style of leadership is likely to see a return to the levels of distrust articulated in the issue identification stage of this study. Alternatively, collaborative leadership could oscillate between the Board's roles as an organizational steward, mediator and catalyst (Ansell \& Gash, 2012). All three roles are important and can be ultilized in performing different aspects of the charter of a national governing body. NSOs are, at different times, required to build social capital across the sport and facilitate outcomes, as was the case in this study. They are also required to act as a mediator to arbitrate and nurture relationships between SMAs, both on the field and off it, and as a catalyst to identify value-creating opportunities, as well as to activate SMAs to ensure the progressive and innovative development of bowls in Australia.

\section{Conclusions}

Limited research has explored the role and application of collaborative governance in federal sport structures. As was argued earlier in this paper, there appears to be a logical application of this form of governance to the Australian sporting context and, indeed, in 
"Exploring the Utility of Collaborative Governance in a National Sport Organization" by Shilbury D, Ferkins L

Journal of Sport Management

(C) 2014 Human Kinetics, Inc.

countries where a similar federal model exists. Through the use of action research, the overall purpose of this study was to enhance the governance capability of the BA Board. Thus, in addressing the first aim of the study, this paper identified what meanings the BA Board attached to the concept of governance capability. Table 1 summarized board responses around the four areas of people, monitoring role, strategic role and relationship with member states. Ultimately, the strategic role, driven by relationships with member states, became the focus for the action and intervention phase of the study.

The decision to use the strategic planning process as a vehicle to implement collaborative governance processes was also based on the Board's view of the constraints and enablers in achieving enhanced governance capability, the second aim of this study. Although the Board was satisfied with its own strategizing, it was of the view that implementing strategy was a significant barrier to good governance. Being "hamstrung by the culture of our sport" was the most powerful message to emerge from this discussion and clearly alluded to the voluntary, amateur heritage and leisure orientation of bowls. It also emphasized that moving to a more professional approach to the governance and management of bowls was not universally accepted by SMAs, and was most acutely experienced in relation to the governance of bowls.

In addressing the third aim of the study, this paper reported on how a developmental action research approach was used to identify which actions could be taken to develop the capability of the BA Board. The advantage of this approach was that the Board played a significant role in identifying how they could best enhance their governance capability. The research team was able to facilitate a dialogue by guiding the Board based on its experiences and knowledge of governance. Using this approach, both practical and theoretical outcomes emerged and, as a consequence, identified the need for a more collaborative approach to governance and its subsequent implementation. In practice, the action research program 
"Exploring the Utility of Collaborative Governance in a National Sport Organization" by Shilbury D, Ferkins L

Journal of Sport Management

(C) 2014 Human Kinetics, Inc.

allowed the board to experience an approach to governance not previously considered or used. They also provided strategic leadership in a collaborative rather than authoritarian setting. However, Board members also recognized the challenge of maintaining a collaborative approach beyond the life of the study. Board leadership emerged as pivotal to the implementation and sustainability of collaborative governance and was most obvious in addressing the fourth aim of this study which considered the implications of such action for governance theory and practice.

Action research is not without its limitations. As with all interpretive approaches which engage qualitative methods, the need to show the influence and interpretations of the researchers is an important part of validity, as is the collaborative and cyclical refinement of issues (Coghlan \& Brannick, 2010). Within space limitations, we have attempted to be clear in each phase, how collaboration occurred and interpretations were derived, and at which point whose 'voice' was being offered. Embedded within this interpretive process was the issue of researcher bias. In addition to the emphasis on transparency, we also took steps to constantly challenge our assumptions. Research participants were constantly involved in checking conclusions and summaries to verify findings. We also spread the tasks between the two researchers to achieve this goal, where one researcher would plan and deliver the workshops, and the other would interrogate thinking during and after the workshop sessions. This also occurred through dual handling of the evaluation interviews. Overall, the challenge of both achieving practical outcomes from a change process and deriving new insights for theory development was a lengthy and resource-intensive process. However, the insights generated about why and how collaborative governance could be enacted and why, in practice, it is so challenging when theoretically it appears so logical, speak to the value of action research. 
"Exploring the Utility of Collaborative Governance in a National Sport Organization" by Shilbury D, Ferkins L

Journal of Sport Management

(C) 2014 Human Kinetics, Inc.

The outcomes of this research point toward the importance of collective board leadership which could be the focus of future research examining how different board leadership styles influence governance behavior at member association level. Moreover, such research could explore, in more depth, the elements of the Ansell and Gash (2008) model of collaborative governance likely to contribute to the sustained implementation of this form of governance. The implementation of collaborative governance is time-consuming and often costly, as was noted by study participants. More evidence is required to assess whether the upfront time and cost devoted to engendering collaborative decision-making is repaid in the longer term via enhanced governance effectiveness, a more coordinated and cohesive strategic direction and consistent implementation of strategic imperatives.

The measures of these outcomes are, essentially, grounded in assessing the starting conditions identified by Ansell and Gash in their model of collaborative governance. The present study demonstrated a positive response to collaborative governance which was exhibited in the changes described in levels of trust, respect, culture, and recognition of the need for a unified vision for bowls. These changes would, therefore, be reflected in revised starting conditions when assessing the starting point for collaborative governance in the future. What is not known is the extent to which this approach can be sustained without the involvement of a neutral facilitator. In other words, what is the board's understanding and capacity for it to assume an ongoing collaborative and collective strategic leadership role in the governance domain? Understanding collective board leadership provides important direction for future research in sport governance settings characterized by a federal model, and has the potential to facilitate deeper insights into leadership in governance and governance in leadership. 
"Exploring the Utility of Collaborative Governance in a National Sport Organization" by Shilbury D, Ferkins L

Journal of Sport Management

(C) 2014 Human Kinetics, Inc.

\section{References}

Adriaanse, J.A., \& Schofield, T. (2013). Analysing gender dynamics in sport governance: A new regimes-based approach. Sport Management Review, 16, 498-513.

Ansell, C., \& Gash, A. (2008). Collaborative governance in theory and practice. Journal of Public Administration Research and Theory, 18, 543-571.

Ansell, C., \& Gash, A. (2012). Stewards, mediators and catalysts: Towards a model of collaborative leadership. The Innovation Journal: The Public Sector Innovation Journal, $17(1), 1-21$.

Auld, C.J. (1997) Professionalisation of Australian sport administration: The effects on organisational decision-making. European Journal for Sport Management, 4(2), 17-39.

Australian Sports Commission (ASC). (2012). Annual report 2011/12. Author: Canberra.

Australian Sports Commission (ASC). (2013). Mandatory sports governance principles. Author: Canberra.

Bolman, L.G., \& Deal, T.E. (2003). Reframing organizations: Artistry, choice, and leadership. John Wiley \& Sons: San Francisco, CA.

Bowls Australia. (2010). Annual report 2009/10. Author: Melbourne.

Bowls Australia (BA). (2011). National bowls census report. Author: Melbourne.

Bowls Australia. (2011). Annual report 2010/11. Author: Melbourne.

Bowls Australia. (2012). Annual report 2011/12. Author: Melbourne.

Cardno, C. (2003). Action research: A developmental approach. Wellington, NZ: New Zealand Council for Educational Research.

Coghlan, D., \& Brannick, T. (2010). Doing action research in your own organization, $3^{\text {rd }}$ edn. Thousand Oaks, CA: Sage.

Denzin, N.K., \& Lincoln, Y.S. (Eds.). (2011). The SAGE handbook of qualitative research, 4th edn. Thousand Oaks, CA: Sage. 
"Exploring the Utility of Collaborative Governance in a National Sport Organization" by Shilbury D, Ferkins L

Journal of Sport Management

(C) 2014 Human Kinetics, Inc.

Emerson, K., Nabatchi, T., \& Balogh, S. (2012). An integrative framework for collaborative governance. Journal of Public Administration Research and Theory, 22, 1-29.

Erakovic, L., \& Jackson, B. (2012). Promoting leadership in governance and governance in leadership: Towards a supportive research agenda. In A. Davila, M. Elvira, J. Ramirez, \& L. Zapata-Cantu (Eds.) Understanding Organizations in Complex, Emergent and Uncertain Environments (pp. 68-83). Basingstoke, UK: Palgrave Macmillan.

Ferkins, L. (2007). Sport governance: Developing strategic capability in national sport organisations. Unpublished doctoral dissertation. Deakin University, Melbourne, Australia.

Ferkins, L., \& Shilbury, D. (2010). Developing board strategic capability in sport organisations: The national-regional governing relationship. Sport Management Review, $13,235-254$

Ferkins, L., McDonald, G., \& Shilbury, D. (2010). A model for improving board performance: The case of a National Sport Organisation. Journal of Management \& Organization, 16, 601-621.

Ferkins, L., Shilbury, D., \& McDonald, G. (2009). Board involvement in strategy: Advancing the governance of sport organizations. Journal of Sport Management, 23, 245-277.

Gustavsen, B. (2006). Theory and practice: The mediating discourse. In P. Reason \& H. Bradbury (Eds.), Handbook of action research: Participative inquiry and practice (pp. 1726). Thousand Oaks, CA: Sage.

Henry, I., \& Lee, P.C. (2004). Governance and ethics in sport. In J. Beech \& S. Chadwick (Eds.), The business of sport management (pp. 25-41). Essex: Pearson Education.

Heron, J., \& Reason, P. (2006). The practice of co-operative inquiry: Research 'with' rather than 'on' people. In P. Reason \& H. Bradbury (Eds.), Handbook of action research: Participative inquiry and practice (pp. 171-178). Thousand Oaks, CA: Sage. 
"Exploring the Utility of Collaborative Governance in a National Sport Organization" by Shilbury D, Ferkins L

Journal of Sport Management

(C) 2014 Human Kinetics, Inc.

Hoye, R. (2007). Commitment, involvement and performance of voluntary sport organization board members. European Sport Management Quarterly, 7, 109-121.

Hoye, R., \& Cuskelly, G. (2007). Sport governance. Sydney: Elsevier.

Hoye, R. \& Doherty, A. (2011). Nonprofit sport board performance: A review and directions for future research. Journal of Sport Management, 25, 272-285.

Lynn, L.E., Heinrich, C.J., \& Hill, C.J. (2000). Studying governance and public management: Challenges and prospects. Journal of Public Administration Research and Theory, 10, 223-261.

Mandell, M., \& Keast, R. (2007). Evaluating network arrangements: Towards revised performance measures. Public Performance \& Management Review, 30, 574-597.

O’Sullivan, G., Hocking, C., \& Spence, D. (2014). Action research: Changing history for people living with dementia in New Zealand. Action Research, 12(1), 19-35.

Robertson, P.J., \& Choi, T. (2012). Deliberation, consensus, and stakeholder satisfaction: A simulation of collaborative governance. Public Management Review, 14, 83-103.

Shilbury, D. (2001). Examining board member roles, functions and influence: A study of Victorian Sporting Organisations. International Journal of Sport Management, 2, 253-281. Shilbury, D., \& Ferkins, L. (2011). Professionalisation, sport governance and strategic capability. Managing Leisure, 16, 108-127.

Shilbury, D., Ferkins, L., \& Smythe, L. (2013). Sport governance encounters: Insights from lived experiences. Sport Management Review, 16, 349-363.

Taylor, M., \& O’Sullivan, N. (2009). How should National Governing Bodies of sport be governed in the UK? An exploratory study of board structure. Corporate Governance: An International Review, 17, 681-693.

Thomson, A-M., \& Perry, J.L. (2006). Collaboration processes: Inside the black box. Public Administration Review, 66 (Special Issue), 20-32. 
"Exploring the Utility of Collaborative Governance in a National Sport Organization" by Shilbury D, Ferkins L Journal of Sport Management

(C) 2014 Human Kinetics, Inc.

Yeh, C., Taylor, T., \& Hoye, R. (2009). Board roles in organisations with a dual board system: Empirical evidence from Taiwanese non-profit sport organisations. Sport Management Review, 12, 91-100. 
"Exploring the Utility of Collaborative Governance in a National Sport Organization" by Shilbury D, Ferkins L Journal of Sport Management

(C) 2014 Human Kinetics, Inc.

Figure 1: Action research model for developing governance capability (adapted from Ferkins et al., 2009)

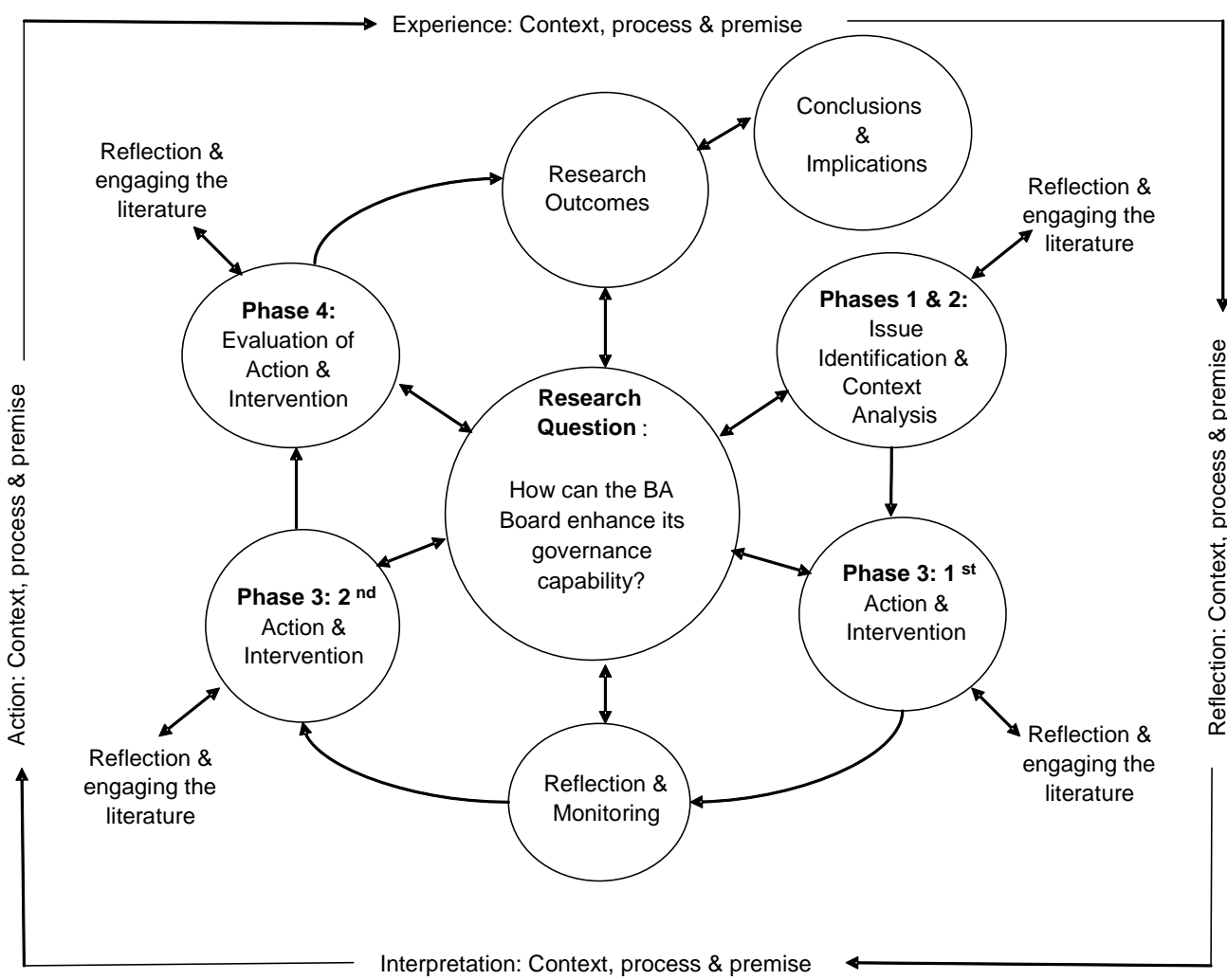


Figure 2: Model of collaborative governance

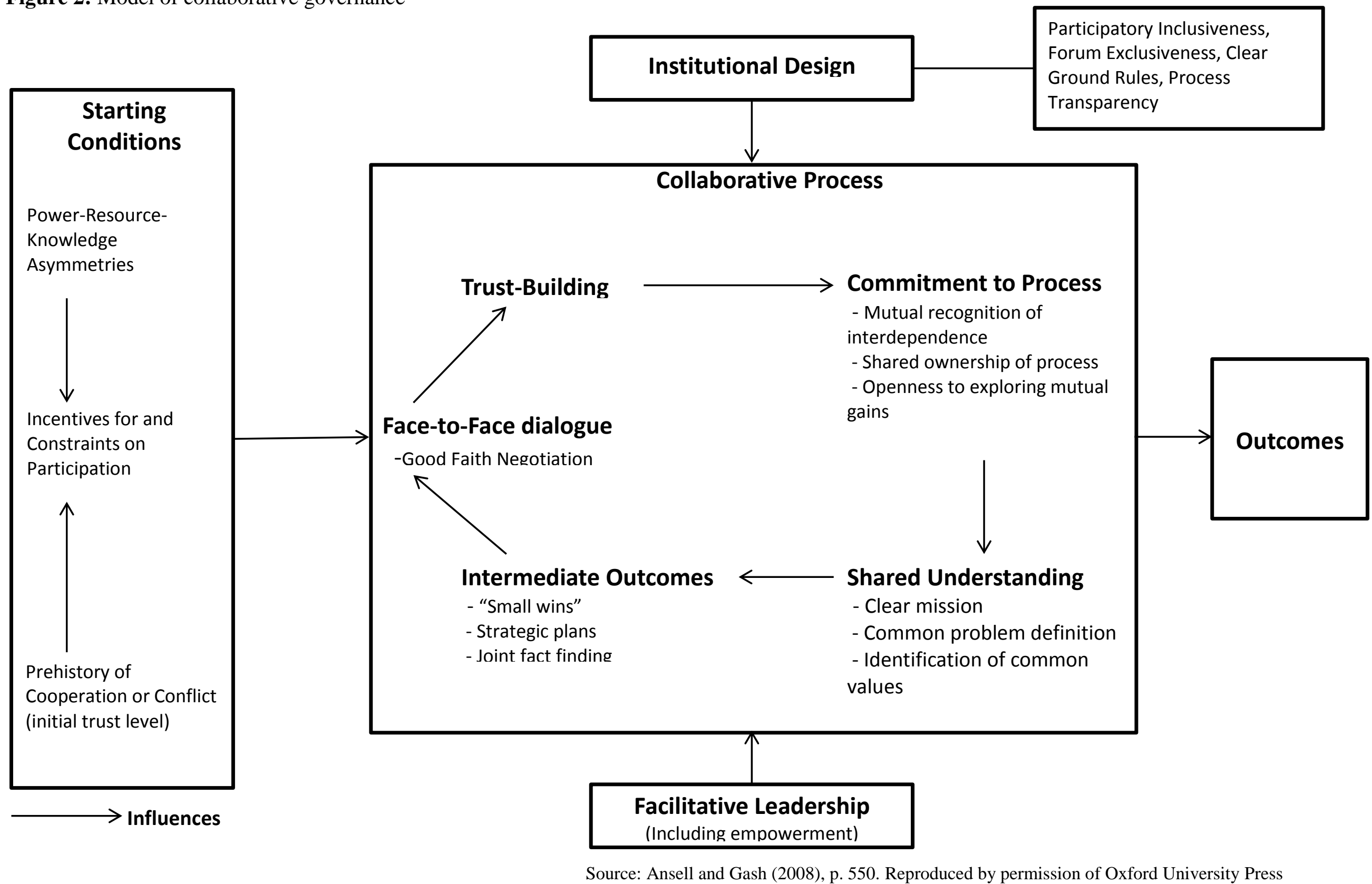


"Exploring the Utility of Collaborative Governance in a National Sport Organization" by Shilbury D, Ferkins L

Journal of Sport Management

(c) 2014 Human Kinetics, Inc.

Table 1: Identifying the Perceived Attributes of a Capable Board

\section{People}

- $\quad$ independence, independent directors so very valuable

- ideal: 50-50 mix of elected and independent

- mix of skills, cross-section of experience, diverse thinking

- respectful, honesty, integrity, innovative

- $\quad$ informed, sport knowledge, experience, business knowledge, professionalism

- chairing skills

- $\quad$ networking skills

- no group thinking

- involved board, high-quality input

\section{Monitoring Role}

- authority, power

- accountability

- financial oversight

- policy

- systems and procedures in place to deal with issues

- remove risk

- monitor CEO performance

- confidentiality

\section{Strategic Role}

- policy

- $\quad$ strategy

- business plan

- oversight of whole

- vision

- leadership toward common goals

\section{Relationships with Member States}

- governing in a unified way

- inclusive

- representative of stakeholders (anyone touched by the sport)

- delivery to members 
Table 2: How Well is the Board Doing?

\begin{tabular}{|c|c|}
\hline Doing Well at ... & Challenging/Doing Less Well at ... \\
\hline $\begin{array}{ll}\text { - } & \text { strategy, strategic issues } \\
\text { - } & \text { national programs } \\
\text { - } & \text { national bontribution to strategy } \\
\text { - } & \text { national-state MOU }\end{array}$ & $\begin{array}{l}\text { - } \\
\text { - } \\
\text { - } \\
\text { contromover in board membership } \\
\text { level } \\
\text { - involving SMA boards in meaningful strategy } \\
\text { discussions }\end{array}$ \\
\hline Constraints & Enablers \\
\hline $\begin{array}{l}\text { - we are hamstrung by the culture of our sport } \\
\text { we are hamstrung by past practices and an old } \\
\text { culture that does not recognize strategic } \\
\text { governance } \\
\text { there is a cultural divide between the top and } \\
\text { bottom of the sport } \\
\text { lack of progress towards professionalization by } \\
\text { the SMAs }\end{array}$ & $\begin{array}{l}\text { - we need different categories of membership } \\
\text { - communication options open to us } \\
\text { - communication of our 'professionalization story, } \\
\text { beyond the national level } \\
\text { attracting those in the sport who can help us } \\
\text { govern strategically at SMA level }\end{array}$ \\
\hline
\end{tabular}


Table 3: Type of Education Recommended

\section{Type of Education}

- BA becomes change agent to facilitate change with SMAs

- Social media is an important mechanism for education

- Need formalized, systematic education process that lasts beyond incumbents (i.e., is passed on when people leave)

- Focus of education is how we influence cultural change

- SMAs need to change governance mechanism to include:

- Improved board structure (i.e., mix of elected and independent, hybrid board composition)

- Improved board behavior (i.e., focus more on the board's strategic role and be conscious of the balance between operational concerns and strategic function)

- Improved board processes (i.e., undertake induction processes)

\section{Enablers}

- Recruitment/induction

- Independent board members

- Look to how we rolled out high performance program through SMAs as example of enabling an educational process

- Look to how we rolled out/nationalized our participation and coaching programs as an example (i.e., success of Community Development Officers program)

- A tool like money will enable change

- Follow-up and follow-through; ongoing and recurring processes

- Face-to-face contact

- Sense of ownership of the process

- Regular meetings with SMA boards

- TRUST

- Just like the whole-of-sport national plan

\begin{tabular}{|c|c|}
\hline Key Issues & Constraints \\
\hline $\begin{array}{l}\text { - } \text { Culture } \\
\text { - } \quad \text { Nurnover in SMA boards } \\
\text { "current" thinkers } \\
\text { - Lack of explicit processes for attracting } \\
\text { - } \text { strategic thinkers } \\
\text { - Cational-SMA relationship is an issue } \\
\text { - Club development - in terms of the business } \\
\text { of running a club }\end{array}$ & $\begin{array}{ll}\text { - } & \text { Costs to SMAs } \\
\text { - } & \text { Some current SMA board members } \\
\text { - } & \text { Process of SMA board member } \\
& \text { recruitment/selection - many come from club } \\
\text { - } & \text { Chammittees } \\
\text { - } & \text { Culture underneath SMAs (i.e., club level) }\end{array}$ \\
\hline
\end{tabular}


"Exploring the Utility of Collaborative Governance in a National Sport Organization" by Shilbury D, Ferkins L

Journal of Sport Management

(C) 2014 Human Kinetics, Inc.

Table 4: Actions Defining Intervention

\begin{tabular}{|c|c|c|c|}
\hline $\begin{array}{l}\text { Mini-Cycles/ } \\
\text { Actions }\end{array}$ & Month & Purpose & $\begin{array}{l}\text { No. of } \\
\text { Participants/ } \\
\text { Interviews }\end{array}$ \\
\hline $\begin{array}{l}\text { Strategic Planning } \\
\text { Workshop }\end{array}$ & April 2012 & $\begin{array}{l}\text { Draft Mission, Vision and agree on } \\
\text { strategic priorities (SP) }\end{array}$ & 45 \\
\hline $\begin{array}{l}\text { Strategic Priority } \\
\text { Workgroups }\end{array}$ & $\begin{array}{l}\text { Round 1: May } \\
\text { to June } \\
\text { Round 2: July } \\
\text { to August }\end{array}$ & $\begin{array}{l}\text { Obtain input on the actions for each SP; } \\
7 \text { groups, } 1 \text { per SP and } 1 \text { working on } \\
\text { Mission \& Vision } \\
\text { Groups composed of a mix of BA and } \\
\text { SMA representatives }\end{array}$ & 5 per group \\
\hline $\begin{array}{l}\text { BA Board Meetings } \\
\text { Phases } 1 \& 2\end{array}$ & $\begin{array}{l}\text { Four Meetings. } \\
\text { June, August, } \\
\text { October, } \\
\text { December }\end{array}$ & $\begin{array}{l}\text { Post-April planning workshop. Update } \\
\text { and reflect on progress, plan next } \\
\text { meetings }\end{array}$ & 9 per meeting \\
\hline \multicolumn{4}{|l|}{$\begin{array}{l}\text { Governance Consultation } \\
\mid \text { Phase } 3\end{array}$} \\
\hline \multicolumn{4}{|l|}{ Board to Board Meetings } \\
\hline $\begin{array}{l}\text { Western Australia* } \\
\text { ACT* } \\
\text { Northern Territory } \\
\text { NSW (Men) } \\
\text { NSW (Women) } \\
\text { Queensland } \\
\text { Victoria* } \\
\text { Tasmania } \\
\text { South Australia* }\end{array}$ & $\begin{array}{l}\text { June } \\
\text { August } \\
\text { September } \\
\text { October } \\
\text { October } \\
\text { November } \\
\text { November } \\
\text { November } \\
\text { December }\end{array}$ & $\begin{array}{l}\text { Invite states to share issues of strategic } \\
\text { significance } \\
\text { Invite input to the strategic plan as it was } \\
\text { evolving } \\
\text { Develop a shared understanding of the } \\
\text { challenges confronting bowls } \\
\text { Build trust and rapport } \\
\text { Foster a common vision for bowls } \\
\text { Seek agreement on using the } 6 \text { SPs to } \\
\text { shape each SMA plan }\end{array}$ & $\begin{array}{l}\text { SMA Board } \\
\text { size ranged } \\
\text { between 7-10 } \\
\text { plus CEO }\end{array}$ \\
\hline BA Board, BA Staff & $\begin{array}{l}\text { October, } \\
\text { November }\end{array}$ & $\begin{array}{l}\text { Obtain input from staff on } \mathrm{SP} \text {, and } \\
\text { actions to support } \mathrm{SP} \text {, also in preparation } \\
\text { for operationalizing plan }\end{array}$ & $\begin{array}{l}14 \text { Staff }+ \text { BA } \\
\text { Board }\end{array}$ \\
\hline State Consultative Body & $\begin{array}{l}\text { October } 2012 \\
\text { April } 2013\end{array}$ & $\begin{array}{l}\text { Monitor progress, confirm Vision \& } \\
\text { Mission }\end{array}$ & $\begin{array}{l}18 \text { plus BA } \\
\text { Board and } \\
\text { CEO }\end{array}$ \\
\hline
\end{tabular}

*Full board to SMA board meeting 